\title{
Antoine Houdar de la Motte, L'Iliade, poème avec un Discours sur Homère. Texte établi sur l'édition originale de 1714
}

\section{Franco Piva}

\section{(2) OpenEdition \\ Journals}

\section{Edizione digitale}

URL: http://journals.openedition.org/studifrancesi/8917

DOI: 10.4000/studifrancesi.8917

ISSN: 2421-5856

\section{Editore}

Rosenberg \& Sellier

\section{Edizione cartacea}

Data di pubblicazione: 1 octobre 2008

Paginazione: 456-457

ISSN: 0039-2944

\section{Notizia bibliografica digitale}

Franco Piva, «Antoine Houdar de la Motte, L'lliade, poème avec un Discours sur Homère. Texte établi sur l'édition originale de 1714», Studi Francesi [Online], 155 (LII | II) | 2008, online dal 30 novembre 2015, consultato il 11 janvier 2021. URL: http://journals.openedition.org/studifrancesi/8917 ; DOI: https:// doi.org/10.4000/studifrancesi.8917

Questo documento è stato generato automaticamente il 11 janvier 2021.

\section{cc) $($ ) $\ominus$}

Studi Francesi è distribuita con Licenza Creative Commons Attribuzione - Non commerciale - Non opere derivate 4.0 Internazionale. 


\section{Antoine Houdar de la Motte, L'Iliade, poème avec un Discours sur Homère. Texte établi sur l'édition originale de} 1714

Franco Piva

NOTIZIA

ANTOINE HOUDAR DE LA MOTTE, L'Iliade, poème avec un Discours sur Homère. Texte établi sur l'édition originale de 1714, avec l'intégralité des illustrations et avec les variantes de l'édition de 1720. Introduction et notes par Francis ASSAF, Toulouse, Société des Littératures Classiques («Collection de Rééditions de textes du xviie siècle»), 2006, pp. 277.

1 Il volume riproduce, per la prima volta dopo l'edizione delle CEuvres de Mr. De La Motte del 1754, L'lliade, il poema in dodici libri che Antoine Houdar de La Motte trasse, nel 1714, dall'lliade di Omero letta nella traduzione in prosa che Mme Dacier aveva pubblicato tre anni prima, e che costituisce la pièce maîtresse dell'ultima parte della celebre Querelle che tra la fine del Seicento e l'inizio del Settecento oppose, a più riprese, Anciens e Modernes. L'Iliade di La Motte suscitò infatti la dura reazione di Mme Dacier che al poema di La Motte e, per certi versi soprattutto al Discours sur Homère che la precedeva, reagì con violenza, ridando in tal modo fiato ad una polemica, quella tra Anciens e Modernes, che si era di fatto conclusa alcuni anni prima. Nella sua lunga «Introduction» Francis Assaf ricostruisce il clima nel quale L'Tliade di La Motte andò ad inserirsi, le diverse posizioni che, di fronte al poema di Omero ed in genere alle opere antiche, assunsero gli Anciens e i Modernes, analizza da vicino la posizione di La Motte, che con la sua Iliade non intese affatto "tradurre" (o tradire) l'Iliade di Omero, bensì adattarla al gusto dei Moderni, le reazioni che la sua operazione suscitò nel campo degli 
Anciens, ed in particolare da parte di Mme Dacier, che si sentì particolarmente chiamata in causa, il significato infine che il suo lavoro poteva avere nel contesto e nel clima letterario del momento. Segue un riassunto-analisi dei dodici libri dell'Iliade di La Motte dal quale risulta che se, «à quelques détails près, La Motte ne rapporte rien qui ne soit dans l'Iliade», egli «ne s'est pas limité à user d'un vocabulaire, d'une rhétorique et d'un style plus adaptés aux perceptions de ses contemporains, mais qu'il a aussi cherché à introduire [nel suo poema] des notions psychologiques et culturelles difficilement décelables voire absentes chez Homère», ma che erano perfettamente in linea con gli obiettivi («attacher» e «émouvoir») che, secondo Houdar, doveva porsi il poeta moderno. Assaf fa ancora notare che, mentre Scarron col suo Virgile travesti aveva inteso «faire rire tout en instruisant», La Motte «lui, a préféré demeurer dans le mode sérieux et proposer une Iliade non pas mièvre et édulcorée, ni défigurée non plus quant à la fabula, par rapport au modèle grec, mais un texte qui, par la réécriture, se veut véritablement français, véritablement moderne, cherchant non pas tellement à instruire en soi, mais surtout à répondre aux attentes d'un lectorat assumant consciemment la modernité, dans un cadre spatio-temporel bien déterminé».

2 Il testo è dato nell'edizione del 1714, integrato, alla fine di ogni libro, dalle varianti (alcune molto significative) introdotte dall'autore nell'edizione del 1720 e riprese in quella del 1754. Come nell'edizione originale, l'lliade è preceduta dall'importante Discours sur Homère, e seguito dall'ode La critique e dalla fable L'Indien et le Soleil, «prononcée à Sa Majesté par l'Auteur, pour le remercier d'une pension». Sono riprodotte anche le illustrazioni che accompagnavano la prima edizione. Per facilitare il confronto, F. Assaf ha riprodotto in Appendice Le premier livre de l'Iliade en vers françois avec une dissertation sur quelques endroits d'Homère pubblicato nel 1700 dall'abbé RégnierDes- marais e la traduzione in prosa del primo canto del poema omerico ad opera di Mme Dacier. Nel complesso si tratta di un'operazione molto interessante, che non mancherà di attirare l'attenzione di quanti a questo importante momento ed aspetto della cultura letteraria francese sono particolarmente attenti. 